\title{
Peri-operative fluid strategy and post-operative acute kidney injury in cardiac surgery patients: any role for pre-operative statin therapy?
}

\author{
Patrick M. Honore, Rita Jacobs, Inne Hendrickx, Elisabeth De Waele, Viola Van Gorp and Herbert D. Spapen
}

See related research by Kim et al., http://www.ccforum.com/content/19/1/350

Acute kidney injury (AKI) is a common complication associated with increased morbidity and mortality in cardiac surgery patients. In this context, the recent paper by Kim et al., showing that a peri-operative liberal 'saline- and starch-based' fluid management significantly enhanced the incidence of severe post-operative AKI in off-pump cardiac surgery patients, is to be acclaimed [1].

With regard to the potential culprit(s) triggering this AKI, the authors pointed at 'usual suspects' such as excess chloride and intrinsic starch-induced renal tubular lesions. However, it is noteworthy that patients in the atrisk group were less likely ( $p=0.001$ !) to be receiving statins before surgery [1]. Statins may prevent kidney injury through inhibition of post-operative inflammatory processes. Compared with statin-naive subjects, cardiac surgery patients taking statins indeed had reduced levels of circulating C-reactive protein, tumour necrosis factor alpha, myeloperoxidase, and pro-inflammatory interleukin (IL)-1, IL-6, and IL-8 and higher concentrations of the anti-inflammatory IL-10 [2]. The largest metaanalysis to date, including nearly 60,000 cardiac surgery patients, revealed a $13 \%$ reduction of post-operative AKI in patients pre-operatively treated with statins [3].

Whether statins embrace the kidney as friend or foe is debatable but probably depends upon the type of study cohort (e.g. septic vs. non-septic), the intervention (e.g. surgery), and pre-existing chronic kidney disease. For example, agent-dependent 'high potency' statin doses increase the risk of AKI in a general patient population [4] whereas the use of corresponding high doses in cardiac surgery patients appears to exhibit a reno-protective effect [5].

\section{Authors' response \\ Ji-Yeon Kim and Eun-Ho Lee}

We thank Professor Honore and colleagues for their interest in our article [1] and their comment. Statin has been widely used in patients with cardiovascular disorders. We agree that the patients in the control group were less likely to be receiving statin before the surgery, which could have affected our results. However, although some clinical studies have suggested a renoprotective effect of statin in patients undergoing cardiac surgery $[6,7]$, there is a lack of evidence to support the beneficial effect of pre-operative statin on renal function after cardiac surgery. Previous studies have reported that pre-operative statin therapy is not associated with a reduced incidence of post-operative AKI [8], including after cardiac surgery [9]. Nevertheless, we tested the impact of pre-operative statin treatment on our results. Although pre-operative statin treatment was not associated with post-operative AKI (odds ratio 0.95 (95\% confidence interval $0.65-1.39$ ), $p=0.78$ ) in a univariate analysis, we

* Correspondence: Patrick.Honore@az.vub.ac.be

ICU Department, Universitair Ziekenhuis Brussel, Vrije Universiteit Brussel,

101 Laarbeeklaan, 1090 Brussels, Belgium 
forced the variable into the final model and there was still a significant association between the renal protective fluid management strategy and post-operative AKI (odds ratio 0.23 (95\% confidence interval 0.14-0.36), $p<0.001$ ). We can therefore definitely conclude that statins had no significant role to play in our observations.

\section{Abbreviations}

AKl: acute kidney injury; IL: interleukin.

\section{Competing interests}

The authors declare that they have no competing interests.

Published online: 29 December 2015

\section{References}

1. Kim JY, Joung KW, Kim KM, Kim MJ, Kim JB, Jung SH. Relationship between a perioperative intravenous fluid administration strategy and acute kidney injury following off-pump coronary artery bypass surgery: an observational study. Crit Care. 2015;19:350.

2. Garwood S. Statins and cardiac surgery. J Cardiothorac Vasc Anesth. 2010;24:909-12.

3. Wang J, Gu C, Gao M, Yu W, Yu Y. Preoperative statin therapy and renal outcomes after cardiac surgery: a meta-analysis and meta-regression of 59,771 patients. Can J Cardiol. 2015:31:1051-60.

4. Dormuth CR, Hemmelgarn BR, Paterson JM, James MT, Teare GF, Raymond $C B$, et al. Use of high potency statins and rates of admission for acute kidney injury: multicenter, retrospective observational analysis of administrative databases. BMJ. 2013;346:f880. doi:10.1136/bmj.f880.

5. Mithani S, Kuskowski M, Slinin Y, Ishani A, McFalls E, Adabag S. Dosedependent effect of statins on the incidence of acute kidney injury after cardiac surgery. Ann Thorac Surg. 2011;91:520-5.

6. Huffmyer JL, Mauermann WJ, Thiele RH, Ma JZ, Nemergut EC. Preoperative statin administration is associated with lower mortality and decreased need for postoperative hemodialysis in patients undergoing coronary artery bypass graft surgery. J Cardiothorac Vasc Anesth. 2009;23:468-73.

7. Virani SS, Nambi V, Polsani VR, Lee W, Elayda M, Kohsaka S, et al. Preoperative statin therapy decreases risk of postoperative renal insufficiency. Cardiovasc Ther. 2010;28:80-6.

8. Argalious M, Xu M, Sun Z, Smedira N, Koch CG. Preoperative statin therapy is not associated with a reduced incidence of postoperative acute kidney injury after cardiac surgery. Anesth Analg. 2010;111:324-30.

9. Nemati $\mathrm{MH}$, Astaneh $\mathrm{B}$. The effects of preoperative statins on the incidence of postoperative acute kidney injury in patients undergoing cardiac surgeries. Interact Cardiovasc Thorac Surg. 2015;21:493-8. 